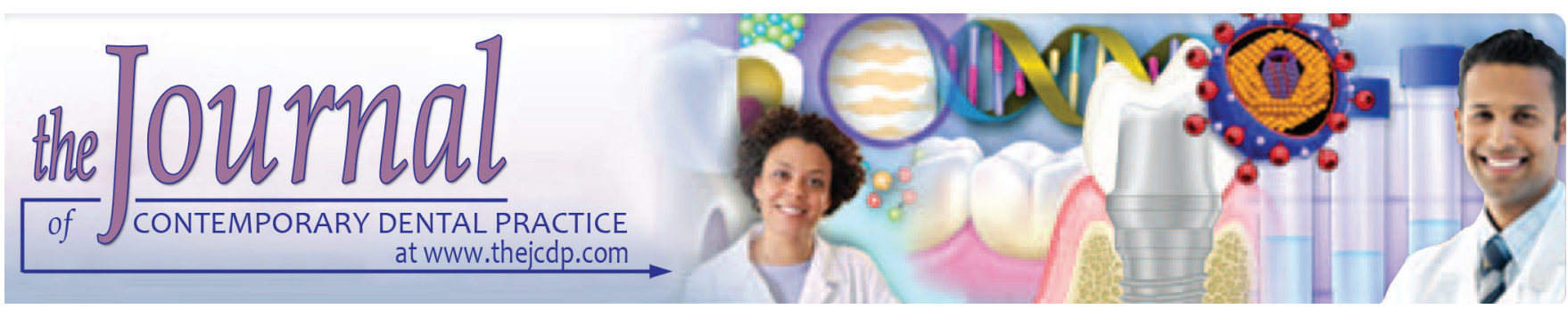

\title{
Association between Ectopic Mandibular and Maxillary Canines
}

${ }^{1}$ Waeil Batwa, ${ }^{2}$ Ibtesam Alzain

\begin{abstract}
Aim: The aims of the present study were (1) to assess the prevalence of ectopic mandibular canines and (2) to evaluate whether an association exists between maxillary and mandibular canine ectopia.
\end{abstract}

Materials and methods: The records of 983 patients (males and females) were divided systematically into two groups: group I (454 patients) (control group) included patients who attended the clinic from September 2013 to August 2014, while group II (529 patients) included patients who attended the clinic from September 2014 to August 2015. Group I was used to assess the prevalence of ectopic mandibular canines in the population, while group II was used to obtain 40 radiographs of ectopic maxillary canines, which comprised group II1. To investigate any association between maxillary and mandibular canines, the prevalence of ectopic mandibular canines was assessed in group II1. Canine positions were assessed as follows: (1) amount of horizontal canine overlap with the adjacent lateral incisor root; (2) the angle between the canine and true vertical.

Results: The prevalence of ectopic mandibular canines in the population (group I) was 5.3\% (24 of 454 patients); in group II1, $22.5 \%$ (9 of 40 ) of maxillary canine cases exhibited ectopic mandibular canines. Group II1 had a significantly higher prevalence of ectopic mandibular canines than did the control group (group I) $(p<0.001)$

Conclusion: The prevalence of mandibular ectopic canines was $5.3 \%$. Ectopic mandibular canines were highly associated with ectopic maxillary canines; a quarter of patients with ectopic maxillary canines are expected to have mandibular ectopia.

Clinical significance: Dentists should be aware of all dental anomalies, particularly, impacted canines. Early and interceptive

${ }^{1}$ Department of Orthodontics, Faculty of Dentistry, King Abdulaziz University, Jeddah, Kingdom of Saudi Arabia

${ }^{2}$ Department of Pediatric Dentistry, Faculty of Dentistry, King Abdulaziz University, Jeddah, Kingdom of Saudi Arabia

Corresponding Author: Waeil Batwa, Department of Orthodontics, Faculty of Dentistry, King Abdulaziz University Jeddah, Kingdom of Saudi Arabia, Phone: +9662565120520 e-mail:wbatwa@kau.edu.sa management of impacted canines increases the chance of canine eruption.

Keywords: Ectopic, Mandibular canines, Maxillary canine.

How to cite this article: Batwa W, Alzain I. Association between Ectopic Mandibular and Maxillary Canines. J Contemp Dent Pract 2018;19(7):830-835.

\section{Source of support: Nil}

\section{Conflict of interest: None}

\section{INTRODUCTION}

Dental anomalies are common in orthodontic patients. Almost $40 \%$ of orthodontic patients have at least one dental anomaly, ${ }^{1}$ including congenitally missing teeth, ectopic eruption, supernumerary teeth, and microdontia. ${ }^{2}$ Cleft orthodontic patients have an even higher prevalence of certain anomalies, including tooth agenesis (maxillary lateral incisors), microdontia, and supernumerary teeth. ${ }^{3}$ Impacted canines are one of several dental anomalies that affect the dentition and require early orthodontic intervention and treatment. ${ }^{4}$ Early assessment of impacted/ ectopic canines is of great importance as early intervention could decrease the likelihood of impaction and reduce the chances of unfavorable outcomes. ${ }^{5-8}$

Impacted maxillary canines have been reported in 1 to $2 \%$ of the population. ${ }^{9-11}$ Although it is not common, any failure to diagnose and treat impacted maxillary canines early may increase the risk of unfavorable sequelae, ${ }^{12}$ such as resorption of the lateral incisor root, cyst formation, ${ }^{13}$ and internal resorption of the impacted tooth. ${ }^{14}$

Two well-known theories have attempted to explain the etiology of impacted (ectopic) canines, namely the guidance theory and the genetic theory. The guidance theory ${ }^{15}$ suggests that local predisposing factors interfere (crowding) with the long path of eruption of maxillary canines and could lead to impaction, mainly including lateral agenesis, peg-shaped lateral incisors, transposition 
of teeth and other mechanical obstructions. ${ }^{16}$ However, the genetic theory suggests that genetic factors are the most influential factors in maxillary canine displacement and subsequent impaction. ${ }^{17}$ The genetic theory is supported by the following evidence: (1) The presence of other dental anomalies associated with impacted canines, (2) bilateral occurrence, and (3) gender, familial, and population associations. Recently, the prevalence, distribution, and sexual dimorphism of dental anomalies among different skeletal malocclusions and growth patterns were investigated, and tooth agenesis and microdontia were significantly more common in class III and hyperdivergent patients. ${ }^{18}$

The presence of dental anomalies (transposition), ${ }^{19}$ lateral agenesis, peg-shaped lateral incisors, ${ }^{20}$ aplasia of the second premolar, infraocclusion of primary molars, enamel hypoplasia, and ectopic eruption of the first permanent molars ${ }^{21}$ associated with impacted canines is evident in the literature. ${ }^{19-23}$

Several studies have investigated impacted/ectopic maxillary canines, but mandibular canines were not examined; the prevalence of ectopic mandibular canines was reported to be $1.16 \%$ in the Indian population. ${ }^{24}$ However, the association between mandibular and maxillary canine ectopia has not been investigated; this topic is interesting because of the genetic involvement of impacted maxillary canines and dental anomalies.

In this study, we aimed to investigate the association between mandibular and maxillary canines and estimate the prevalence of impacted/ectopic mandibular canines in the studied population.

\section{MATERIALS AND METHODS}

We obtained ethical approval from the Ethical Research Committee of the Faculty of Dentistry. A systematic randomized approach was adopted to collect and review the records of the selected dental patients (males and females). The records of patients who attended the clinic between September 2013 and August 2015 were retrieved from the pediatric dentistry clinic database for this retrospective, cross-sectional study.

The retrieved records were divided into two groups: group I (control group) included records of patients who attended the clinic from September 2013 to August 2014, while group II included records of patients who attended the clinic from September 2014 to August 2015. Both groups were matched, and duplicate candidates were removed. The control group (group I) was used to assess the prevalence of ectopic mandibular canines in the population. Group II was used to obtain 40 radiographs of ectopic maxillary canines, which comprised group II1. Then, to investigate any association between maxillary
Flow Chart 1: Sample distribution chart. Ectopic mandibular canines were diagnosed in 24 of 454 patients in the control group and in 9 of 40 patients in group II1 according to panoramic radiographs. All the group II1 patients had impacted maxillary canines

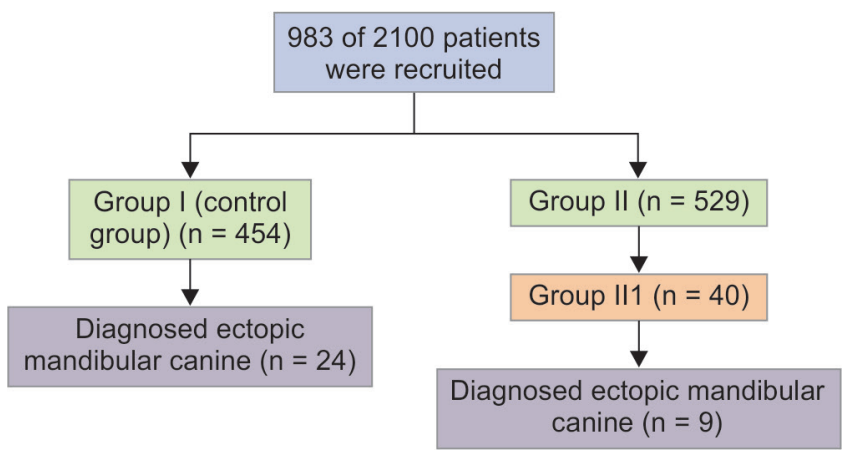

and mandibular canines, the prevalence of ectopic mandibular canines was assessed in group II1 (Flow Chart 1).

The patient inclusion criteria were as follows: (1) Aged 8 to 15 years, (2) presence of a panoramic radiograph with acceptable quality that had been taken within the target age range, and (3) well-documented progress notes of dental treatment. The exclusion criteria were as follows: (1) Missing canines or lateral incisors either due to hypodontia or extraction, (2) the presence of a craniofacial anomaly, such as cleft lip/palate or other anomalies, (3) history of or currently active orthodontic treatment, such as interceptive treatment, expansion, and/or extraction, (4) severe labial crowding that jeopardized accurate assessment of the panoramic radiograph, and (5) presence of facial asymmetry.

All panoramic radiographs were taken with a single radiograph machine (CS 8100SC system, Carestream Dental Limited Company, Atlanta, Georgia, USA). The machine settings were standardized and adjusted for all patients according to the School of Dentistry, Department of Paediatric Dentistry guidelines and the manufacturer's instructions $(68 \mathrm{kV}, 8.0 \mathrm{~mA}, 17.9 \mathrm{~S})$. All panoramic radiographs were recorded in a digital format and stored using Carestream practice management software; Carestream Ortho Track software (CS Ortho Track System, Carestream Dental Limited Company, Atlanta, Georgia, USA) was used to measure the angle between the true vertical and the long axis of the canine. The true vertical was set perpendicular to the true horizontal. The true horizontal was established during patient positioning before radiograph recording by asking the patient to bite on a plastic stick projecting from the machine and aligning the patient's interpapillary line parallel to a laser beam that projected from the machine to the face that had previously been adjusted to be parallel to the floor (Fig. 1). The long axis of the canine was drawn from the tip off the canine crown through the anatomical crown and the root to the apex of the root.

To assess the risk of canine impaction and/or ectopia, the best available evidence in the literature was adopted 


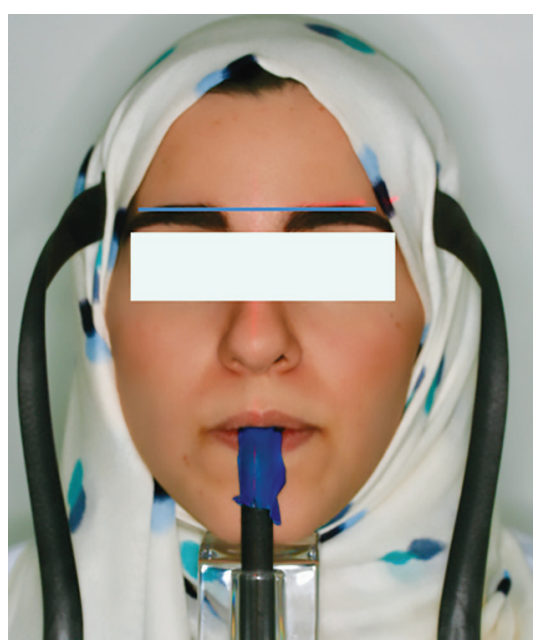

Fig. 1: The true horizontal was established by aligning the face so that the interpapillary line (blue) was parallel to the laser beam projecting on the face (red). The blue strip was a tangent line showing the parallelism of the interpapillary space to the laser beam

and applied to the collected panoramic radiographs. The evidence was most robust regarding the criteria of ectopic/impacted maxillary canines, and the adopted criteria are summarized in Table $1 .{ }^{25,26}$ Ectopic mandibular canine features or criteria were significantly less prevalent in the literature, yet two studies suggested several criteria that were relatively similar to the maxillary canine criteria, and these are summarized in Table $1.27,28$

The canine positions were assessed as follows: (1) Amount of horizontal canine overlap with the adjacent lateral incisor root and (2) the angle between the canine and true vertical. The position of the canine was categorized as ectopic if one or more of the categories suggested ectopia (Table 1).

The radiographs were assessed by an experienced orthodontic consultant; 30 radiographs were reassessed 2 weeks later to validate reliability.

\section{Statistical Analysis}

As the study compared the prevalence (differences in percentages) of ectopic/impacted canines between groups I and III, a chi-squared test was used to assess the differences

Table 1: Criteria for assessing the position of the canine

\begin{tabular}{|c|c|c|c|}
\hline Tooth & Criteria & Good position & Ectopic position \\
\hline \multirow[t]{2}{*}{$\begin{array}{l}\text { Maxillary } \\
\text { canine }\end{array}$} & Overlap & $\begin{array}{l}\text { Canine does not } \\
\text { horizontally overlap } \\
\text { lateral root }\end{array}$ & $\begin{array}{l}\text { Canine crosses } \\
\text { lateral incisor } \\
\text { root midline }\end{array}$ \\
\hline & $\begin{array}{l}\text { Angulation to } \\
\text { true vertical }\end{array}$ & $0-45^{\circ}$ & $>45^{\circ}$ \\
\hline \multirow[t]{2}{*}{$\begin{array}{l}\text { Mandibular } \\
\text { canine }\end{array}$} & Overlap & $\begin{array}{l}\text { Canine does not } \\
\text { horizontally overlap } \\
\text { lateral root }\end{array}$ & $\begin{array}{l}\text { Canine crosses } \\
\text { lateral incisor } \\
\text { root midline }\end{array}$ \\
\hline & $\begin{array}{l}\text { Angulation to } \\
\text { true vertical }\end{array}$ & $0-30^{\circ}$ & $>30^{\circ}$ \\
\hline
\end{tabular}

in categorical data between the groups (groups I and II1), and the level of significance was set at 5\% $(p \leq 0.05)$. Statistical Package for the Social Science (IBM SPSS Statistics for Windows, version 21.0, IBM Corp, New York, USA) was used to analyze the data.

\section{RESULTS}

The records of 2,100 patients were allocated and investigated according to the inclusion and exclusion criteria. Of these 2,100 patients, a total of 983 patient records met the inclusion criteria and were further examined.

\section{Control Group (Group I)}

The control group (group I) included 454 patients, with a mean age of 10.26 years, ranging from 8-13 years. The patients included 236 males (52\%) and 218 females $(48 \%)$. Totally, 24 cases $(5.3 \%)$ of ectopic mandibular canines were recorded in this group. Of the 24 patients who presented with ectopic canines, $6(25 \%)$ had bilateral canine involvement, while $18(75 \%)$ had a unilateral canine; of those 18 canines, 7 (38.8\%) were diagnosed on the left side, while 11 (61.2\%) were on the right side. The 24 ectopic canines were equally distributed between males and females. Twelve were in males (50\%) and 12 were in females (50\%); the ages in these 24 cases ranged from 8 to 12 years with a mean age of 11 years (Table 2).

\section{Group II}

Group II consisted of 529 patients ranging from 8 to 13 years with a mean age of 10.11 years. Males accounted for $49.7 \%$ of the group with 263 individuals, while females represented the other $51.3 \%$, with a total of 266 individuals. The sole purpose of this group was to extract all the cases with ectopic maxillary canines. Forty ectopic maxillary canine cases were found in this group.

\section{Test Group (Group II1)}

Group II1 included 40 patients with ectopic maxillary canines, with a mean age of 11.12 years. Totally, 22 of the patients $(55 \%)$ were male, while $18(45 \%)$ were female, and $9(22.5 \%)$ of these patients had ectopic mandibular canines. Of these ectopic mandibular canines, four were bilateral, and five were unilateral (three left and two right). The age range of the patients with ectopic maxillary

Table 2: Demographic and biographic data related to the sample

\begin{tabular}{|c|c|c|c|c|}
\hline Variable & \multicolumn{2}{|l|}{ Group I } & \multicolumn{2}{|c|}{ Group II1 } \\
\hline $\begin{array}{l}\text { Age (mean } \pm \text { SD; } \\
\text { range) }\end{array}$ & \multicolumn{2}{|c|}{$(10.12 \pm 1.57 ; 8-13)$} & \multicolumn{2}{|c|}{$(11.2 \pm 1.38 ; 8-13)$} \\
\hline Gender & Male & Female & Male & Female \\
\hline & $275(52 \%)$ & $254(48 \%)$ & $22(55 \%)$ & $18(45 \%)$ \\
\hline
\end{tabular}

SD: Standard deviation 
Table 3: The distribution of ectopic canines in groups I and II1

\begin{tabular}{|c|c|c|c|c|c|c|}
\hline & \multicolumn{2}{|c|}{ Presence vs absence } & \multicolumn{2}{|c|}{ Unilateral vs bilateral } & \multicolumn{2}{|c|}{$\begin{array}{c}\text { Right vs left (unilateral } \\
\text { cases only) }\end{array}$} \\
\hline & Presence & Absence & Unilateral & Bilateral & Right & Left \\
\hline Group I (control group) & $24(5.3 \%)$ & $430(94.7 \%)$ & $18(75 \%)$ & $6(25 \%)$ & $11(61 \%)$ & $7(39 \%)$ \\
\hline Group II1 (test group) & $9(22.5 \%)$ & $31(77.5 \%)$ & $5(55.6 \%)$ & $4(44.4 \%)$ & $2(40 \%)$ & $3(60 \%)$ \\
\hline
\end{tabular}

Table 4: Intergroup comparison of ectopic canine prevalence

\begin{tabular}{lllll}
\hline & $\begin{array}{l}\text { Yes } \\
\text { (present) }\end{array}$ & $\begin{array}{l}\text { No } \\
\text { (absent) }\end{array}$ & Total & $\begin{array}{l}\text { p-value (chi- } \\
\text { square variate) }\end{array}$ \\
\hline Group II1 & $9(22.5)$ & $31(77.5)$ & 40 & $0.000^{\text {I }}(17.47)$ \\
Control group I & $24(5.3)$ & $430(94.7)$ & 454 & \\
\hline $\mathrm{p}<0.001$ & & &
\end{tabular}

and mandibular canine was 10 to 13 years, with a mean age of 10.77 years. Additional details on the canine side and position are presented in Table 3.

To examine the association of mandibular and maxillary canines, the prevalence of ectopic mandibular canines in the test group (II1) was compared with that in the population or control group (group I). Table 4 shows that group II1 had a significantly $(\mathrm{p}<0.001)$ higher prevalence of ectopic mandibular canines than did the control group (group I). A chi-squared test was applied with a 95\% confidence interval to test the effect of age and gender on the presence of impacted canines and the age of diagnosis; however, no statistically significant effect was found ( $p>0.05)$, thus excluding the influence of age and gender on the above variables ( $\mathrm{p}=0.71$ and 0.84 respectively). An interreliability test (Cronbach's alpha) showed a value of 0.80 , indicating a strong level of agreement.

\section{DISCUSSION}

The association of impacted maxillary canines with other dental anomalies, such as hypodontia, enamel hypoplasia, infraocclusion, and ectopic eruption of the first permanent molars ${ }^{21,22}$ motivated us to investigate its association with mandibular canines. This association of dental anomalies suggests some genetic involvement in the postnatal growth of facial structures, affecting both the craniofacial and occlusal relationship and dental development. ${ }^{18}$

The inclusion and exclusion criteria were carefully set for this study. Patients as young as 8 years were included, as this age was suggested by Ngan et $\mathrm{al}^{4}$ to investigate for ectopic canines. The presence of panoramic radiographs was important; the panoramic view is typically used in addition to visual examination and palpation to confirm canine impaction. ${ }^{29}$ Patients with previous or current orthodontic treatments were excluded, since such treatments may resolve the impaction and ectopia via interceptive treatment, and these treatments are suggested at an earlier age. ${ }^{6-8}$ Moreover, missing lateral incisors could influence the path of eruption of the permanent canines. ${ }^{30}$
The presence of labial crowding makes canine measurements challenging because the overlapped teeth and facial asymmetry make establishing the true horizontal difficult. Finally, craniofacial anomalies are usually associated with missing teeth, especially the incisors, ${ }^{31}$ which could influence the canine eruption pattern. Therefore, these variables have been excluded.

In the present investigation, all efforts were made to match (age and gender) the control group (I) to the experimental group (II1); moreover, we ensured that both groups represented the same untreated orthodontic population. Several study models have been suggested previously, ${ }^{21,32}$ and our model followed the model suggested by Baccetti. ${ }^{21}$ Dividing the sample into two main groups, groups I and II1, allowed us to compare the mandibular canine prevalence between these groups. Group I served as the control group and revealed the prevalence of mandibular canines in the population $(5.3 \%)$. This percentage is considered relatively high, especially when compared with both the value of $1.16 \%$ reported in the Indian population ${ }^{24}$ and when compared with the 1 to $2 \%$ prevalence of ectopic maxillary canine in the literature., ${ }^{9,10}$ The nature of our sample (dental patients) may have contributed to this significant difference in prevalence between the two populations.

The prevalence of ectopic mandibular canine in control group (group I, 5.3\%) and test group (group II1, $22.5 \%$ ) was compared in Table 4, where an increase in the prevalence was noted in group II1 (the ectopic maxillary canine group). This difference in prevalence was highly significant $(p<0.001)$, which suggests that the chance of having ectopic mandibular canine is higher when there are ectopic maxillary canines and an association between maxillary and mandibular ectopic canines. This association was reflected in the $22.5 \%$ relative risk of patients with ectopic maxillary canines having ectopic mandibular canines. Therefore, a quarter of patients with ectopic maxillary canines are expected to have mandibular ectopia. Although the mean ages of groups I and II1 were 10.26 and 11.12 , with almost equally distributed gender (slightly more males than females), our sample did not demonstrate any gender or age association with ectopia, and the majority of patients with ectopic canines were diagnosed at approximately 11 years of age. Our findings showed that mandibular canine impaction was more often unilateral than bilateral. This finding is 
consistent with maxillary canine impaction patterns, in which the chances of having unilateral canine impaction are four times greater than bilateral impaction. ${ }^{33}$ We did not detect any difference between males and females in the prevalence of mandibular canine impaction, unlike maxillary impaction, which was more common in females than males (2.3 to 1$).^{33}$

This is the first time that ectopic mandibular canines have been associated with maxillary canine ectopia. The association of other dental anomalies has been investigated previously, and an association was found among ectopic maxillary canines, ectopic eruption of the first molar, infraocclusion of the primary molar, and aplasia of premolars. ${ }^{34}$ Ectopic canine eruption increased significantly when any other condition was present. This finding supports the hereditary theory of dental anomalies and strongly suggests the possibility of a genetic relationship among the number, size, shape, and structural characteristics of teeth, which reflects the polymorphic nature of the anomalies. The association between ectopic maxillary and mandibular canines in this study indicated genetic involvement, although congenitally absent maxillary lateral incisors have been recorded 2.4 times more frequently in populations with palatally impacted canines than in the general population ${ }^{15}$. We suggest that this phenomenon is a biological variation ${ }^{20}$ that is genetically influenced and controlled.

The number of records included in group II1 and the recruitment of all the patients from one center limited our sample. Further multicenter studies are needed to examine the associations of other dental anomalies with ectopic maxillary and mandibular canines. Ideally, cone beam tomography should be used to diagnose ectopic/ impacted teeth and associated root resorption; ${ }^{35}$ however, this would involve excessive radiation, which could not be justified if no added diagnostic value was obtained.

\section{CONCLUSION}

The prevalence of ectopically erupting mandibular canines was $5.3 \%$. Ectopic maxillary canines were highly associated with ectopic mandibular canines; a quarter of patients with ectopic maxillary canines are expected to have mandibular ectopia. Further studies are needed to determine the associations of other dental anomalies with ectopic mandibular canines.

\section{CLINICAL SIGNIFICANCE}

Dentists should be aware of all dental anomalies and, particularly, their association with impacted canines. This could help prevent dentists from overlooking impacted canines when assessing these anomalies, and dentists need to be trained to competently diagnose and manage these anomalies. Early and interceptive management of impacted canines increases the chance of canine eruption from 64 to $91 \%{ }^{5,36}$

\section{REFERENCES}

1. Uslu O, Akcam MO, Evirgen S, Cebeci I. Prevalence of dental anomalies in various malocclusions. Am J Orthod Dentofacial Orthop 2009 Mar;135(3):328-335.

2. Afify AR, Zawawi KH. The prevalence of dental anomalies in the Western region of Saudi Arabia. ISRN Dent 2012 Jun; 2012:837270.

3. Germec Cakan D, Nur Yilmaz RB, Bulut FN, Aksoy A. Dental anomalies in different types of cleft lip and palate: is there any relation? J Craniofac Surg 2018 Feb.

4. Ngan P, Hornbrook R, Weaver B. Early timely management of ectopically erupting maxillary canines. Semin Orthod 2005 Sep;11(3):152-163.

5. Ericson S, Kurol J. Early treatment of palatally erupting maxillary canines by extraction of the primary canines. Eur J Orthod 1988 Nov;10(4):283-295.

6. Naoumova J, Kurol J, Kjellberg H. A systematic review of the interceptive treatment of palatally displaced maxillary canines. Eur J Orthod 2011 Apr;33(2):143-149.

7. Naoumova J, Kurol J, Kjellberg H. Extraction of the deciduous canine as an interceptive treatment in children with palatally displaced canines - part II: possible predictors of success and cut-off points for a spontaneous eruption. Eur J Orthod 2015 Apr;37(2):219-229.

8. Naoumova J, Kurol J, Kjellberg H. Extraction of the deciduous canine as an interceptive treatment in children with palatal displaced canines-part I: shall we extract the deciduous canine or not? Eur J Orthod 2015 Apr;37(2):209-218.

9. Langberg BJ, Peck S. Adequacy of maxillary dental arch width in patients with palatally displaced canines. Am J Orthod Dentofacial Orthop 2000 Aug;118(2):220-223.

10. Shapira J, Chaushu S, Becker A. Prevalence of tooth transposition, third molar agenesis, and maxillary canine impaction in individuals with Down syndrome. Angle Orthod 2000 Aug;70(4):290-296.

11. Sajnani AK. Permanent maxillary canines—review of eruption pattern and local etiological factors leading to impaction. J Investig Clin Dent 2015 Feb;6(1):1-7.

12. Alzain I, Batwa W, Kamrani A, Bawazir R. Early assessment of ectopic maxillary canine. EC Dent Sci 2017 May;10(5): 125-131.

13. Brown LH, Berkman S, Cohen D, Kaplan AL, Rosenberg M. A radiological study of the frequency and distribution of impacted teeth. J Dent Assoc S Afr 1982 Sep;37(9):627-630.

14. Ericson S, Kurol J. Resorption of maxillary lateral incisors caused by ectopic eruption of the canines. A clinical and radiographic analysis of predisposing factors. Am J Orthod Dentofacial Orthop 1988 Dec;94(6):503-513.

15. Becker A, Zilberman $Y$, Tsur B. Root length of lateral incisors adjacent to palatally-displaced maxillary cuspids. Angle Orthod 1984 Jul;54(3):218-225.

16. Becker A, Chaushu S. Etiology of maxillary canine impaction: a review. Am J Orthod Dentofacial Orthop 2015 Oct;148(4): 557-567.

17. Peck S, Peck L, Kataja M. The palatally displaced canine as a dental anomaly of genetic origin. Angle Orthod 1994;64(4): 249-256. 
18. Fernandez CC, Pereira C, Luiz RR, Vieira AR, De Castro Costa M. Dental anomalies in different growth and skeletal malocclusion patterns. Angle Orthod 2018 Mar;88(2):195-201.

19. Shapira Y, Kuftinec MM. Maxillary tooth transpositions: characteristic features and accompanying dental anomalies. Am J Orthod Dentofacial Orthop 2001 Feb;119(2):127-134.

20. Peck S, Peck L, Kataja M. Prevalence of tooth agenesis and peg-shaped maxillary lateral incisor associated with palatally displaced canine (PDC) anomaly. Am J Orthod Dentofacial Orthop 1996 Oct;110(4):441-443.

21. Baccetti T. A controlled study of associated dental anomalies. Angle Orthod 1998 Jun;68(3):267-274.

22. Baccetti T. A clinical and statistical study of etiologic aspects related to associated tooth anomalies in number, size, and position. Minerva Stomatol 1998 Dec;47(12):655-663.

23. Ali B, Shaikh A, Fida M. Association between sella turcica bridging and palatal canine impaction. Am J Orthod Dentofacial Orthop 2014 Oct;146(4):437-441.

24. Gupta SK, Saxena P, Jain S, Jain D. Prevalence and distribution of selected developmental dental anomalies in an Indian population. J Oral Sci 2011 Jun;53(2):231-238.

25. McSherry PF. The assessment of and treatment options for the buried maxillary canine. Dent Update 1996 Jan-Feb;23(1): 7-10.

26. Pitt $S$, Hamdan A, Rock P. A treatment difficulty index for unerupted maxillary canines. Eur J Orthod 2006 Apr;28(2): 141-144.

27. Arnautska H. Persistent deciduous mandibular canines as the cause of impaction of permanent mandibular canines. Int J Sci Res (IJSR) 2015 Aug;4(8):1876-1879.
28. Howard RD. The anomalous mandibular canine. Br J Orthod 1976 Apr;3(2):117-121.

29. Shapira Y, Kuftinec MM. Early diagnosis and interception of potential maxillary canine impaction. J Am Dent Assoc 1998 Oct;129(10):1450-1454.

30. Becker A, Gillis I, Shpack N. The etiology of palatal displacement of maxillary canines. Clin Orthod Res 1999 May;2(2): 62-66.

31. Freitas JA, Garib DG, Oliveira M, Lauris Rde C, Almeida AL, Neves LT, Trindade-Suedam IK, Yaedú RY, Soares S, Pinto JH. Rehabilitative treatment of cleft lip and palate: experience of the Hospital for Rehabilitation of Craniofacial Anomalies-USP (HRAC-USP)—part 2: pediatric dentistry and orthodontics. J Appl Oral Sci 2012 Mar-Apr;20(2):268-281.

32. Seow WK, Lai PY. Association of taurodontism with hypodontia: a controlled study. Pediatr Dent 1989 Sep;11(3):214-219.

33. Ericson S, Kurol J. Radiographic examination of ectopically erupting maxillary canines. Am J Orthod Dentofacial Orthop 1987 Jun;91(6):483-492.

34. Bjerklin K, Kurol J, Valentin J. Ectopic eruption of maxillary first permanent molars and association with other tooth and developmental disturbances. Eur J Orthod 1992 Oct;14(5):369-375.

35. Ericson S, Kurol J. Incisor root resorptions due to ectopic maxillary canines imaged by computerized tomography: a comparative study in extracted teeth. Angle Orthod 2000 Aug;70(4):276-283.

36. Baccetti $\mathrm{T}$, Leonardi M, Armi P. A randomized clinical study of two interceptive approaches to palatally displaced canines. Eur J Orthod 2008 Aug;30(4):381-385. 